\section{Seeing the Wolf through Sami Eyes - Understanding Human Dimensions of Wildlife Conflict in Northern Sweden}

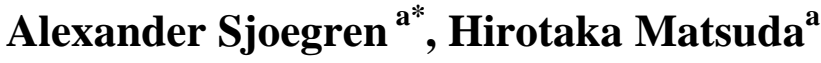 \\ ${ }^{a}$ University of Tokyo, Graduate School of Frontier Sciences, 5-1- \\ 5 Kashiwanoha, Kashiwa City, T277-8563, Japan \\ Received: September 30, 2015/ Accepted: March 11,2016
}

\section{Abstract}

Human-Wildlife Conflict (HWC) is a sustainability issue in that it has social, economic as well as environmental costs. It has been defined as an overlap in the requirements of humans and wildlife, but an increasing body of research recognizes that HWC is just as much about conflict between humans about animals. Research on these human dimensions of HWC often focus on the "rural-urban divide" where conflicts of interest between human stakeholders are described as the result of differences in underlying beliefs about human's place in nature, property rights, etc. between protectionist-oriented urban creators of environmental policies, and rural utilitarianoriented receivers of the effects of said policies. Indigenous people tend to have believes about nature and wildlife markedly different from that of the majority populations in their countries, however, research on HWC where one of the stakeholders is an indigenous group of people is lacking. In order to address this research gap, the present study investigated a HWC in northern Sweden, where the indigenous, reindeer-herding Sami people are pitted against Swedish authorities and NGOs regarding carnivore policy due to livestock predation issues. While the relatively rare wolf tends to kill a smaller number of reindeer annually than other carnivore species, presence of wolf in the reindeer herding area is especially opposed by the Sami, contributing to making the traditionally controversial species a focal point of environmental debate in Sweden. In order to investigate why the wolf is especially controversial to the Sami, as well as assessing the role of Sami "indigenousness" in the HWC in question, semi-structured interviews were conducted with members of three different Sami villages, exploring Sami relationships to nature, their livestock, carnivores, the wolf, Swedish authorities and the Swedish general public. The interviews were analyzed using a number of concepts previously employed in HWC; perceived power relationship to nature (subjugation/domination), perceived value of nature (material/intrinsic), wildlife value orientations (mutualism/dominance), need structure (materialist/post-materialist) and access to social power (high/low). Analysis of interview transcripts points to Sami having a submissive attitude towards nature, assigning nature an intrinsic value, relating to wildlife in a mutualistic manner, not placing material needs first, but having a low access to social power. This strongly suggests that the HWC situation with wolf and reindeer herding in northern Sweden must be understand foremost from a perspective of social power (and lack thereof) rather than as a result of conflicting environmental values. As for values, the Sami have a strong protectionist value orientation, but have environmental priorities different from that of Swedish authorities. This implies that on a general level, when indigenous peoples are stakeholders in HWC, it is important to consider their view of nature and man's place in it, or any attempts to reconcile their interests with those of other stakeholders will fail due to misinterpretation of their true intentions, with continued social friction and failure of gaining acceptance for, and thus success of, environmental policy.

Keywords:Human-wildlife; Sami; Wolf; Sweden; Nature Perception; Wildlife Value Orientations

\section{Abbreviations:}

\begin{tabular}{|lcl|}
\hline HVC & $:$ & Human-Wildlife Conflict \\
WVO & $:$ & Wildlife Value Orientations \\
RHA & $:$ & Reindeer Herding Area \\
\hline
\end{tabular}

\section{Introduction}

\subsection{Human-wildlife conflict}

As long as humans and wildlife have shared living space, there has been human-wildlife conflict (HWC). HWC has been defined as "an overlap in the requirements of humans and wildlife" (World Parks Congress, 2003). HWC is problematic to both humans and wildlife; through crop raiding and predation of livestock, wildlife causes damage to human property, which in many cases causes humans to hunt and kill the wildlife responsible for the damage. More systematic implementation of lethal control of wildlife has had effects such as range collapses of species, trophic cascades and even species extinctions [1].

Corresponding Author

Tel.: +81-80-9578-7332; E-mail: alesjo@sustainability.k.u-tokyo.ac.jp 
Further, wildlife can attack and kill humans. A dramatic example of this can be found in Northeast India, where more than 1150 humans and 370 animals died as a result of human-elephant conflicts between 1980 and 2003 [2]. While the number of people killed by wildlife annually might be small in a global context, such incidents, as well as wildlifeincurred damage on property affects the social acceptance of wildlife locally and regionally, as well as tolerance for conservation policies of the species in question [1]. Over time, HWC has been increasing as a consequence of expansion of human settlements and loss of wildlife habitat; this is especially evident when it comes to big animals with requirements for large habitats, such as elephants [3] and large carnivores [4]. Further, this is especially true for developing countries with growing human populations. In the developed world, increased conflicts instead tend to be a product of wildlife protection policies, having allowed animal species to increase their populations and reclaim habitat earlier lost to human expansion [5], [6]. The case study of this article belongs to this latter type of HWC. Overall, HWC is considered a serious global issue that needs addressing for ensuring the livelihoods and safety of groups as people, as well as conservation goals for individual species and overall ecosystem integrity [1].

\subsection{Human dimensions of HWC}

When wildlife management institutions originally emerged, their purpose was to see to the needs of rural agrarian communities, such as regulation of game animals for hunting and predator control for protection of livestock. However, as the populations of the developed world gradually became urbanized, a shift in values followed, as a result of changes in lifestyle such as specialization in work, separation from food production, paving ways for new ways of assigning meaning to nature and wildlife, different from the classic utilitarian mindset [7]. In rural areas, where values tend to be more traditional, the effects of wildlife are often also most felt. As a result, in as well developing as developed countries, HWC becomes a conflict between different social groups with different ideas of how to manage wildlife, often falling across the urban-rural divide [1]. Further, conflicting ideas about proper wildlife management practices may not only reflect beliefs and values about wildlife itself, but ultimately differences in more fundamental, underlying social beliefs about for example tradition, private property rights and governmental control [7], [8], [9], [10]. Recognizing these human dimensions of HWC might be essential for solving them.

\subsection{Indigenous perspectives}

While HWC is a useful concept for understanding humans' interaction with wildlife, it is important to acknowledge that there are limitations to a Western, scientific approach to this topic. Indigenous people tend to have complex, nuanced relationships with animals that simply don't fit into a typical HWC framework, although it might seem like it at first glance. For example, the Maasai pastoralists of Tanzania and Kenya experience predation on their livestock by lions, and they are of course negative towards such behavior on the part of the lions. Further, among the Maasai, there is a traditional form of lion hunting, olamayio, carried out by young men, ilmurran. From a strict western perspective it is easy to interpret the lion hunt as a means of retaliation on the part of the Maasai, and as a potential threat to the lions sharing their land. However, olamayio is an old tradition with many positive connotations and Maasai typically express gratefulness to the lion for providing its life to the hunt and the festivities around it. Even when describing livestock predations lions are described in a positive manner; their intelligence (they visit the human settlements two times to assess the situation, and hunt on the third) and their modesty (they only kill what they can eat, as opposed to for example hyenas and jackals). There are also old tales about lions helping and protecting Maasai [11].

On a more general level, indigenous people tend to have unique knowledge about the nature and wildlife they are in contact with, some of which may seem like superstition from a scientific perspective but proves very much valid upon further inspection. Among native American hunters, certain individuals of various wildlife are called "keepers of the game", and it is said that these individuals should not be hunted, if so they will make their whole species unobtainable for further hunting. Pierotti (2010) puts forth studies showing that in a cohort of an animal species, certain individuals constituting less than $10 \%$ (typically older and larger) might contribute $75-90 \%$ of the recruits to following generations. He further argues that Western political and economic pressures have led to an emphasis on harvesting the largest individuals of animals in hunting and fishing, accelerating the collapse of their populations because of their disproportionate reproductive contribution. These larger individuals, he argues, are in fact "the keepers of the game" the Native Americans refer to, and their demise very much has broader ecological and economic consequences [12]. It is therefore evident, that a strictly Western perspective might lead to missing aspects of the often complex relationships between humans and wildlife, as well as knowledge on how to properly interact with nature. In this study, the relationship between the indigenous Sami people, the government and the wolf in Sweden was investigated.

\subsection{The Sami people}

The Sami are the indigenous people of northern Sweden, Norway, Finland and Russia. They inhabit an area spanning over the four countries traditionally called Sapmi. Though having pursued a number of different livelihoods historically, they are most famous for reindeer husbandry, a culture they only share with a few indigenous peoples of Siberia. Today the total number of Sami is thought to be 
around 80 ooo of which roughly a fourth, 20 ooo, live in Sweden. The Sami has been historically discriminated, as the governments of the nation states that were established within Sapmi sought to integrate them with the cultural majority. As part of this, Sami were christened, forbidden to use their own native tongue and their children were put in residential schools to get "proper" education and values. Today, no such official discrimination exists, but the historical discrimination by the Swedish is reverberates within the Swedish Sami community. The Sami are represented politically by the Sami Parliament of Sweden (Sametinget or Samediggi) which main responsibility is to raise Sami influence in Sweden. Among their tasks is to collect statistics from the reindeer herding industry which forms the basis for economic compensation, etc from the Swedish government. Also worth mentioning, SvenskaSamernasRiksförbund is a politically independent interest organization that foremost represents the reindeer herding minority among the Sami. (Sapmi). In Sweden, the Sami were officially recognized as an indigenous people only in 1977, but this status is not established in the constitution, as is the case with Finland. Further, while Norway has ratificated the ILO Convention 169, which ensures protection of indigenous peoples from assimilation and protects their right to continue their traditional culture, Sweden has not [13].

\subsection{A brief overview of modern reindeer husbandry in Sweden}

Today 4600 Sami own reindeer, and of these 2500 individuals depend on reindeer husbandry for their primary income. The yearly net revenue of the Reindeer industry is 2,5 million EUR (as of 2014), which is less than the yearly turnover of Swedish wild meat production produced by hunting. While reindeer husbandry has become modernized over the past decades with the use of snowmobiles, GPS and computers, the basic premise for modern day reindeer husbandry is the same as it has always been; the reindeer are free-ranging and sustained through natural grazing, and a year of reindeer herding is centered on the animals' yearly migration from their summer pastures to the winter pastures and back. The reindeer are only rounded up at a few occasions for specific purposes, such as tagging of calves, separation of one's own reindeer from those of the neighboring Sami villages and for slaughter. Fodder is only given to reindeer during severe winters when grazing conditions are especially poor and is a large additional expense for the reindeer herder. Traditionally, the Sami moved together with their herds on foot and ski and thus had a nomadic lifestyle. Today this lifestyle remains, although alleviated by means of car transportation and access to multiple "permanent" homes. Also, often due to barriers in the landscape such as dammed rivers, roads, etc., reindeer are often transported by trucks certain parts of their migration route. As mentioned above, the Sami don't own their traditional land, but have a specific legal right for utilizing it for reindeer husbandry. This means that they can use wild vegetation for producing meat, which is their primary source of income. Other products from reindeer include hides and handcraft made from reindeer antlers [14].

Reindeer herding is conducted within the reindeer herding area (RHA) which occupies $52 \%$ of Sweden's total surface, situated in the northern half of the country. The organizational unit of reindeer herding is the siida, or Sami village. There are currently 51 Sami villages in Sweden, each containing a number of business units or companies, renskötselföretag. There are currently about 900 such companies in Sweden. Each company, usually consisting of a family unit of herders, owns a certain number of reindeer, its size varying with the size of pasture the siida provides. Each Sami village is allowed a maximum amount of reindeer depending on the grazing carrying capacity of this area, the number is calculated to be close to the ecological optimum. The current total number of reindeer in Sweden varies between 225 ooo and 280 ooo individuals [14]. Reindeer herding in Sweden is regulated through Rennäringslagen, a law established in 1971. According to this law, the Sami has exclusive rights to utilize their traditional land (corresponding to the RHA) for reindeer husbandry. The parts of the RHA situated in the fells above the grain boundary (as well as some additional lowland areas) are called "year-round land" and here reindeer may be kept year round. Additionally, reindeer may be kept in the so called winter pastures, i.e. lowland and coastal lands of the RHA, from the ist of October to the 3oth of April. In practice, both types of areas are utilized throughout a year of herding, following the natural migration of the reindeer. For conducting reindeer husbandry the Sami must be member of a siida, and the siida must not conduct other commercial activities besides reindeer husbandry. Individual reindeer herders however have the right to have other sources of income than reindeer herding. Further, the right to conduct reindeer husbandry is dependent on the continuous use of the pastures, a certain number of years of discontinued reindeer husbandry results in the right being revoked [15]. Laws serving the same purpose as Renskötsellagen are found in Norway and Finland. A major difference in Finland is that non-Sami citizens there are also allowed to conduct reindeer herding [13]. On an ecological level, the grazing of the domesticated reindeer owned by the Sami is an ecosystem service which corresponds to the grazing performed by the wild reindeer originally inhabiting the landscape. Would the grazing pressure currently being applied to the landscape by the reindeer cease, drastic changes in the composition of the vegetation of the landscape would result, with opportunistic, fast-growing plant species pushing back more sensitive species dependent on exposure to sunlight, resulting in local or even regional reduction of biodiversity [16]. 


\subsection{Reindeer herding and the great carnivores; damages and compensation}

The four great carnivores of Sweden; wolf, bear, lynx and wolverine, are protected by the EU Habitat directive, and their numbers has been increasing during the past few decades as a result of conservation policies. As a result, depredation of reindeer has increased as well and the Sami Parliament has reported a 33\% decrease in annual reindeer for 2013/2014 compared to 1996 (see table 1 and 2, respectively). In a 2013 government report, it is estimated that between 19500 and 72500 reindeer are killed by carnivores. Among these, the lynx is estimated to take 10-50 ooo reindeer, the wolverine 6-1500 reindeer, the bear 35007500 reindeer whereas the number for wolves is 75-150 [17]. While originally based on the number of reindeer found killed, the current compensation system (since 1996) is based on occurrence of predators. For wolf, lynx and wolverine there are set compensation rates for temporary and permanent occurrences within Sami villages and number of rejuvenations. Occurrence and reproduction of these three species is determined through census carried out during the winter by regional government officials, often aided by reindeer herders. For the bear, which hibernates during winter, a different system is used which is based on an assessment of the number of bears per unit area. This assessment is an extrapolation from a reporting system utilized by Swedish hobby hunters. However, there have been doubts on the accuracy on the census of wolf, lynx and wolverine from the side of reindeer herders as well as government representatives. Further, for a long time no upper limit was set for how much depredation a siida should have to be able to tolerate, regardless of compensation levels. As of late 2013, a new bill on Swedish carnivore policy stated that no siida should have to tolerate more than $10 \%$ loss of its annual slaughter outtake to predators [17]. While being a big step forward for Sami rights on a formal level, the practical implementation of this policy has not yet been fully worked out at the time of this writing. Another way of dealing with carnivore predation is through various forms of preventive measures. Livestock owners can receive subsidies for measures such as fencing. Fencing can however never be used as more than a temporarily measure in reindeer husbandry since the reindeer are free-ranging and migrate over long distances in search of pastures. Further, hunting can be used as a regulatory measure. There are two types of hunting for this purpose, licensed hunting and nuisance wildlife management (NWM). Whereas licensed hunting is a general permission for a certain number of a carnivore to be killed off through hunting, NWM is aimed at certain carnivore individuals causing damage in a certain area. Licensed hunting in Sweden is carried out for bear and lynx, but not for wolf and wolverine. In Sweden, all hunting is regulated in the law Jaktförordningen from 1987. Permission for NWM requires applying for certain permission, however, paragraph 28 in Jaktförordningen allows a livestock owner to shoot a carnivore attacking their livestock if he or she is present during the attack and witness it. With shooting a carnivore comes the responsibility to prove it was carried out in self-defense[17].

\subsection{Reindeer husbandry and the wolf}

Like in much of the Western world, the wolf was persecuted until relatively recently in Sweden. The Swedish government issued a bounty on wolves in 1647, greatly stimulating a nation-wide hunt resulting in the eventual extermination of the species in the country. Not until 1966 the campaign stopped as the wolf earned protected status. This was, however, also the year the last known wolf in Sweden was shot [18]. In the early 1980 , a single wolf pair which had immigrated from the east established themselves in the Värmland area in the central part of Sweden. These became founders of a new Swedish wolf population which today number around 250 individuals, as of summer 2014 [17]. Since the majority of the Swedish wolf population stems from the offspring of this couple and three other immigrants, it is genetically weak and effects of inbreeding have been documented in many individuals [17]. The wolf has since its return been a controversial subject in Sweden, as a number of stakeholder groups have been negatively affected by the species. Leisure hunters meet competition for hunting game, additionally their hunting dogs, which are running loose during hunts, often get killed by wolves. Livestock owners have had to withstand attacks on their animals, and this is also the case for the Sami [19]. The wolf has protected status through the EU Habitat directive, which Sweden, as a member country of the European Union, must follow. The EU Habitat directive states that any species listed in its appendices, of which the wolf is one, must be maintained in Favorable Reference Populations (FRP) by the member countries in which it resides. For a species to achieve FRP status, it must have a population size, genetic variation and habitat large enough for it to be considered viable in a long-term perspective. It is, however, up to the respective member states to decide whether this goal has been achieved or not for the species in question. As of late 2013, the official stance of the Swedish government is that FRP has been achieved for the Swedish wolf population [17]. However, no real consensus has been achieved within the Swedish wolf researcher community; the reason for this is the difficulty in determining the exact long-term effects of the abovementioned poor genetics of the population (Personal communication, wolf biologist at Grimsö Wildlife Research Station). When asked about their relationship to the wolf, reindeer herders typically claim that wolves are incompatible with reindeer husbandry. While claiming that presence of lynx, bear and wolverine is acceptable at "reasonable" levels, they typically demand zero presence of wolves. The reason given for this is the specific hunting technique of the wolf. Whereas for example the lynx is a stealth killer very well capable of killing a reindeer without the rest of the herd noticing, the wolf relies on scaring and exhausting its prey. The main problem with a wolf attack 
may therefore not be the number of reindeer actually killed, but the fact that the rest of the herd becomes scattered requiring days or even weeks of work to re-gather, resulting in massive amounts of extra labor. Traditionally, night-time guarding against wolves was a big part of reindeer husbandry, a practice making use of traditional knowledge about the terrain, weather and the behavior of reindeer and wolves. While the wolf has been described as problematic to Sami historically, other stories indicate that the Sami relationship with wolves was not only one of animosity [20]. However, due to the temporary disappearance of wolves in Sweden, as well as modernization of reindeer husbandry, the traditional knowledge on guarding against wolves has been discontinued [18]. Further, as reindeer herders typically have larger herd today it is harder to guard them the traditional way. Also, often being able to reach a permanent or temporary home by car at the end of the working day, herders typically leave their herds alone during the nights.

A 2008 bill proposed that wolves should be allowed to temporarily occur, but not establish territories in the RHA. The 2013 bill on predator policy claims that due to the need of genetic reinforcement to the Swedish wolf population, single wolf rejuvenations should be allowed in parts of the RHA where they do "least damage". During the winter of 2013, the establishment of a genetically important wolf female (named G 82-10) was allowed in the southern part of the RHA for this reason. Her presence caused severe disruption among the reindeer of the area, resulting in much controversy and large public spending on preventive measures. The case has become instructing in being careful with establishment of wolf territories in the RHA [17]. An important aspect of the Sami reluctance to accept wolves is the effect it has on their public image among majority Swedes. In general, public sentiment towards wolves is becoming more positive over time, and people negative towards wolves tend to belong to stakeholder groups directly affected by their presence, such as livestock owners; these groups tend to be in the minority. For the Sami, already a minority in the Swedish society already facing prejudice and lack of understanding, their animosity towards the wolf tends have negative consequences on the social level as well [21].

\section{Methodology}

\subsection{Semi-structured interviews/general}

The primary data was collected through semi-structured interviews with Sami reindeer herders, in order to get an indepth understanding of the informant's motivations, experiences and opinions regarding reindeer herding in the presence of wolves. In addition, a number of structured interviews were carried out with government officials, ecologists and NGO members to get broad, balanced and up-to-date picture of the studied HWC. Information obtained from these interviews in turn served to instruct the outline for the semi-structured interviews with the reindeer herders.

\subsection{Choice of study area and sampling}

The southern part of the RHA area was selected for study area. The reason for this was that in the south the reindeer husbandry area borders to a region which contains the majority of Sweden's wolf population. Young wolves born in this area tend to walk northwards when looking for territories to establish themselves in, which means that southern Sami villages has regular encounters with wolves (personal comment EPA informant). Bear, lynx and wolverine also occur throughout the area to various degrees. The three Sami villages from which informants contributed the study are VilhelminaNorra, Idre and Jinjevaerie. All initial contact with reindeer herders was made through the informant at the Environmental Protection Agency, who knew them through her work. It is not always easy to gain the trust of Sami people since they experience negative sentiments from majority Swedes, especially when it comes to carnivore issues (personal comment, EPA informant). Thus, while generally targeting informants in southern Sami villages, interviewees were chosen on the basis of personal connections.

\subsection{Interview technique}

Interviews were carried out in semi-structured form, i.e. while general themes were established; the questions themselves were open in character, allowing the informants to discuss the themes more freely. This format facilitated for the informants to open up and share even quite personal thoughts and ideas. To further facilitate communication, the interviews were opened by a self-introduction by the researcher, followed by a self-introduction by the informant(s). All interviews were carried out in Swedish and documented through field notes and audio recording, and ranged from one to two and a half hours in length.

Since the purpose of the interviews was to explore the informants' values and beliefs regarding nature and wildlife, a few open-ended questions were used as the backbone of the interviews, while ensuring that the informant could talk freely. Most of the time, all of these questions did not need to be asked, since the informants tended to answer some of them automatically while telling their stories, sometimes even during their self-introductions. This was especially the case for the group interview, where a significant portion was used by the informants to describe a year in their Sami Village, which brought up several themes. The open-ended questions were the following:

1. What is your relationship to nature?

2. What is your relationship to the reindeer?

3. What is your relationship to carnivores?

4. What is your relationship with the wolf? 
5. What is your opinion on how carnivore manage-ment is currently carried out in Sweden?

6. What does it mean to be Sami in Sweden today?

\subsection{Informants and locations}

Below follows an account of the informants and where the interviews took place. The names of the informants have been changed to ensure their anonymity.

Semi-structured interview 1:

VilhelminaNorra Sami Village (130815)

This interview was carried out as a group interview with a retired reindeer herder "Sven" and two of his grown children, "Ingrid" and "Hans", both active reindeer herders in VilhelminaNorra Sami Village. The interview was conducted in their family home in the village Kittelfjäll and lasted for two and a half hours.

Semi-structured interview 2:

Idre Sami Village (140326)

The informant in this interview, "Joel", is not only a reindeer herder, but has a high-ranking position in SvenskaSamersRiksförbund, the main interest organization for reindeer herders in Sweden. The interview took place at their office in the city Östersund, the county seat of Västerbotten County. The interview lasted for about an hour.

Semi-structured interview 3:

Jinjevaerie Sami Village (140326)

The last informant interviewed was "Lisa", reindeer herder in Jinjevaerie Sami Village. The interview was carried out in a common room in Gaaltije, a Saami culture center in Östersund, and lasted for about an hour.

Table 1 List of interviews, informants and locations

\begin{tabular}{llllll}
\hline $\begin{array}{l}\text { Interview } \\
\text { no. }\end{array}$ & Location & Name & Gender & Age & $\begin{array}{l}\text { Saami } \\
\text { Village }\end{array}$ \\
\hline 1 & Kittelfjäll & "Ingrid" & Female & 5os & V. Norra \\
1 & Kittelfjäll & "Sven" & Male & 4os & V. Norra \\
1 & Kittelfjäll & "Hans" & Male & 70 Oos & V. Norra \\
2 & Östersund & "Joel" & Male & 50 Oos & Idre \\
3 & Östersund & "Lisa" & Female & 5os & Jinjevaerie \\
\hline
\end{tabular}

\subsection{Analytical framework}

Five different concepts used or suggested for addressing the human dimensions of HWC present in previous literature on the subject were employed for analysis of the interview data:

- Perceived power relationship to nature (subjugation/domination): Whereas huntergatherer societies see themselves as dependent on the whims of a powerful natural environment, the shift to pastoral societies marked a shift to a domination worldview, where humans perceived themselves as rising above nature and shaping it according to their needs. [22]

- Perceived value of nature (instrumental/intrinsic): Whereas some people foremost see nature as a storehouse of resources which can be translated into capital, others believe nature's value is independent of its economic utility [22].

- Wildlife Value Orientations (WVO): A person with a dominant $\mathrm{WVO}$ value wildlife according their economic contribution or the damage they might cause; hence they typically divide animals into "good" and "bad" categories. A person with a mutualistorientation on the other hand think animals have intrinsic value, believe that they have rights, deserve care and respect, and that humans can have relationships of mutual trust with them. A pluralist holds a combination of the above values, whereas a distanced person have little interest in/opinion about wildlife at all [23].

- Materialist-post-materialist need structure: When a society achieves a certain level of prosperity, values shift from being predominantly about economic and physical security, to being more about self-expression and quality of life. A range of these values can however be found in one and the same society, and whereas materialists have more emphasis on nature use, post-materialists emphasizes protection [22].

- Differential access to social power: The environmental agenda tend to be dominated by a middle-class, urbanized worldview whose followers know little about the life in the rural area where the results of wildlife policies is most felt. Rural populations on the other hand, seldom able to affect the policies in question, feel disempowered and alienated from the political mainstream [8]. 


\subsection{Data Analysis}

First, complete transcripts were made for each interview in their entirety. Second, the transcripts were analyzed with the use of the abovementioned concepts. In practice, the transcripts were screened for certain keywords and key phrases that revealed the informant's stance regarding a specific concept.

Example 1:

"I usually say that, it is not me who has this right; it is the reindeer that carries the right. But that's my opinion..."

Stating that animals have rights is typical for a person with a mutualistic wildlife value orientation.

Example 2:

"[Reindeer herding] is my life. Of course one has the goal to be able to make a living but that is not the (primary) goal, to make money. To be a reindeer herder is to have a lifestyle and then one has to realize one has to yield to... the vagaries of the weather and the needs of the reindeer."

This quote reveals two things. First, that being a reindeer herder is not primarily about making money for the interviewee. Second, that it requires an acceptance of having to down to nature, which is characteristic of a subjugation view on nature.

\subsection{Translation of results}

Upon analysis, all relevant interview sections were translated from Swedish to English for use in this paper.

\section{Results \\ 3.1. Interview extracts}

The following section is a presentation of extracts from the transcript, chosen from their relevance for the themes explored.

\subsubsection{Relationship to nature}

Of the interviewed informants, Joel was the one to elaborate the most on man's place in nature as a whole, how Sami specifically perceive it and why:

"Man is part of nature, just like a carnivore, or reindeer or moose or something, so... [...] And we have this holistic outlook, in that way a landscape without human presence is also strange, in my opinion. [...] For a while you could almost get the impression that when a natural preserve was established it was in order to protect nature from all human influence. It was almost as if man should not be allowed to exist in nature. But now the tides have fortunately enough turn, as I perceive it [...] "I think we have a different sense of reverence so to speak, another respect for nature. And our culture... we haven't used up nature, we haven't raised any concrete monuments or something of the kind. [...] It is [because of] the reindeer, it is really the reindeer that utilizes the land, and we live off the reindeer and hunting and fishing... And then it is important to economize the resources for ensuring long-term survival. And we get this during our upbringing, respect towards wildlife and nature."

\subsubsection{Relationship to the reindeer}

The informants in the group interview spoke more about the significance of reindeer husbandry to Sami culture as a whole than just the animal alone.

Hans: It is culture. Had it not been for reindeer husbandry, there would be no Sami culture left. It would have perished. Ingrid: We have woodwork handcraft that carries the alliance with the reindeer. There is also the joik (traditional Sami singing), it tells a lot about places, about reindeer, the nature... A lot is connected to the reindeer. There is language as well, Sami has expressions for the reindeer and so forth. There are various forms of culture, but it is the reindeer husbandry which is the usage of the land [...] If the reindeer does not utilize the land [...] we won't have the right to utilize the land (either). [...] I usually say that, it is not me who has this right; it is the reindeer that carries the right. But that's my opinion...

Ingrid: We have a lot of freedom in our work [...] It is not just a line of work for us, it's a way of life...

Hans: I would say the feeling for the reindeer, I guess it never changes, it lives on... [...] You always have that feeling.

Joel: I have great respect for the reindeer, and its ability to survive in an extreme environment. And yes, I of course want the best for the reindeer. And I want to treat it with both reverence and respect. [...] The reindeer dictates the life of the herder. I usually generalize and state that if the reindeer is happy, I am happy. If the reindeer is satisfied, I am satisfied. [...] Even if we know that a reindeer will be slaughtered we treat it with utmost respect. It should be treated in a humane way all the way up to... when we slaughter it. And afterwards, when it has given its life to us, we have to treat the products from the reindeer with great respect and reverence... also, take care of the meat and make the best out of it, so that nothing goes to waste, so that no reindeer has died in vain, so to speak. [Reindeer husbandry] is my life. Of course one has the goal to be able to make a living but that is not the [primary] goal, to make money. To be a reindeer herder is to have a lifestyle and then one has to realize one has to yield to... the vagaries of the weather and the needs of the reindeer. [...] And long-term planning can be real difficult, for example within a family, it all depends on the behavior of the reindeer, what season and weather it is, what the conditions of the pastures are, and so forth. But... I wouldn't want to change 
with anyone. No. But I feel tremendously proud to be a reindeer herder and... wouldn't want to have another kind of life. [...]Further, one has a strong culture, a strong identity, and... I can tell from my own children that they have no problem with identity. And its joyful, one is Sami, reindeer owner and... The children grow up and know this and feel tremendously... satisfied with it.

Lisa: You know, it is complicated, because you can be so angry with them [the reindeers]... Sometimes they are sulky, and you drag on, but you always end up with the same insight, it is me who don't understand. Maybe you want to pull them in a certain direction, and it doesn't work, and you struggle and all. [...] it always ends in the same manner, there is something I haven't understood, and when you do understand you blush a little and think about how silly you were... [...] The other side of it, however, is this bottom-less love that... It hurts terribly, even when it (the reindeer) is well. That is, even when you see it is alright, your soul hurts because you know that when darkness falls, you can't protect it any longer, and this you know every single night. [...] We are the only ones that protect them. Against everything, it is we who at least try to bring them to their pastures and defend the land, where would the reindeer go if we hadn't fought for generations for there to be any land?

\subsubsection{Relationship to carnivores}

Stories about carnivores ranged from accounts of attacks on reindeer to more general thoughts on these animals place in nature and the life of the reindeer herders. It was however generally hard to receive thoughts on the animals alone, as the policies surrounding them seemed to be a defining factor in how they were related to.

Ingrid: We have lived with carnivores, and we have always accepted that... Where they do the least damage, they may dwell. Because if the Lap (old, derogative word for Sami) had not tolerated carnivores, there would not be any left today.

Joel: They [carnivores] don't really have a function when it comes to reindeer husbandry. But we of course understand that they are part of nature.

Lisa: One has great respect for them... Respect, but also a delight mingled with terror, but also... they are impressive animals. I have nothing against the animal itself. I have no intention to exterminate any species whatsoever. However, there are situations where they have the real upper hand. And since we have to live in a market-based world... it would be another thing if we could just live in a biological world, but now our lot is to live in a market-based world. A context, and therefore... We have to generate profit in order to survive. And because of this there are situations where we are pressured and must be allowed to defend ourselves.

Apart from the wolf, the bear was frequently talked about, usually in terms of respect or even friendship:

Joel: I suppose it is the myths surrounding the bear, one says it has one man's wit and twelve mens' strength... And the bear, he can really act in such a way that you become... mesmerized by its behavior. I suppose that is what has made a respect for the bear emerge. Yes, they have a way about them that makes people both admire and in some cases fear them.

Lisa: I have a deep respect (for the bear), and the times we have killed a bear we actually have had ceremonies and worship, you don't dare anything else. (...) I am convinced he has power to take revenge if you don't watch out... It is said that the bear and the Sami have an agreement, there is tales about that... The Sami realized that one must sleep and humans don't have night vision, and the bear has another capacity for smelling. [...] We have a communion with the bear that he will be allowed to feed himself, but just so he can get his fill and nothing more... But he is also supposed to protect the herd. [...] I have not been able to study it, but I know that other carnivores have great respect for the bear...

\subsubsection{Relationship to wolves}

As for the wolf, the replies were very similar among the informants, typically negative and unforgiving. The reason for especially disliking the wolf was its hunting technique which causes the reindeer herds to scatter, causing the herders massive amounts of additional work, apart from the actual loss of livestock. All informants agreed that the wolf and reindeer husbandry is incompatible. A recurring story was that in past, reindeer herders had lost all their livestock, become "reindeer-less", because of the wolf. This was used as a justification for wanting wolves off the reindeer herding area in the present day.

Sven: Yes, he (the wolf) is the worst, there exists nothing worse.

Hans: You see, if there is a wolf, no... it's the worst there is since he scatters (the herd) so terribly and then he kills. [...] You know, in the old days he could kill so that a whole family went bankrupt. I heard he chased the whole herd over a cliff's edge. They went reindeer-less. Then we had a relative who lived down by the lake and received 300 reindeer, and they had such bad luck that the wolf took them all [...] they became fisherman Sami again.

Sven: One has heard stories since way back, why so many Laps, as we were called then, stayed down in the lowlands and started farms. It was because they had gotten a wolf among the reindeer and lost them all, they had lost control over the reindeer [...] he does not only kill, he scatters as well.

Ingrid: Times change. [...] We lived in a kåta (traditional temporary Sami dwelling) and heard stories about... The wolf is simply the worst, that... Come what may, as long as it is not the wolf. And we thought, no worry, because there are no wolves, but now we live in a reality that the wolf [...] will be around increasingly. [...] 
When asked if there was a reasonable level of wolves to occur, as with the other carnivores, they replied:

\section{Ingrid: There we have zero tolerance}

Sven: Sweden has had zero tolerance way back, if you start to read the history. [...] and the wolf has not been living in Sweden [for a while] after all, so the [current] Swedish wolf population is not unique in any way. Because he descends from the Finnish-Russian population which has several thousands of animals.

Ingrid: Of course there were wolves, but then you had the fur hunters as well, they were around, and they hunted, and if there was a wolf in the area you hunted, people worked together, until it was caught. [...] ...as soon as you discovered a wolf track, there was a battue. [...] You could ski into a farm and say "I'm pursuing a wolf", and someone else would take over.

Joel: The wolf, we can't accept it in the reindeer herding area, because it has such a behavior, you know, it doesn't just kill the reindeer, it scatters reindeer herds and it... it makes a rational reindeer husbandry impossible. [...] The reindeer is a creature of habit, and you can teach it to take a certain route when it wanders between the summer and winter pastures. [...] And we had such well-planned reindeer herding in our Sami village that we could predict how the reindeer would act at certain seasons and weather conditions. But the wolf has ruined that for us by now. [...] He scatters the herd in all directions and then they won't return there because it is connected to danger, and then they spread and take other routes, which creates a lot of extra work.

Lisa: Wolves and reindeer herding don't go along with each other. They don't, it's a utopia. [...] I have experience of it myself by now. It's in our history, my grand-grandfather became reindeer-less... because of the wolf. And you see, they have a way of moving about and hunting... and that they can appear in packs, and... that they are so powerful and run and move and... no, it doesn't work and they scatter and so forth... You see, we have a strict responsibility to keep our reindeers in check, it is our property, it just doesn't work...

\subsubsection{Relationship to the government and the general public}

The general theme when talking about their relationship to the government was that of disappointment and mutual distrust. Especially the current carnivore policy was heavily questioned, and all informants identified it as the problem for reindeer husbandry in Sweden currently. A main recurring theme was the feeling of powerlessness in changing one's situation.

Ingrid: If the predation pressure had not been as severe as it is today, we would have had... really, more money, because now many are forced to take other jobs, to... you can't sell as much calves, you can sell male calves, but not female calves since the herd is not growing. [...] Sweden has lost control over the present carnivore politics. And we have organizations that are sabotaging the management. [...] They say the surface of Sweden is so large, that there can be so many wolves in Sweden. The government has decided that there should be no wolves in the summer pastures, but we spend half of the year in the winter pastures, and it's just as bad to have wolves there. And we want help so that we don't have to have wolves (at all) among the reindeer. [...] Nowadays, we don't even have permission to protect our animals. We have paragraph 28 but it's [for] direct attacks, you have to be there when the carnivore... [attacks] [...] The carnivores wear you down [...] you see the damage that they do and you don't get the help (you need) and it turns into frustration, in the Sami villages, in the family... [...] You have this worrying, this psychological part where you think, like [...] if you carry out a paragraph 28 for example, [...] you get exposed a lot, as a Sami village... because the wolf is a very protected animal. [...] For all other people, they don't really understand, they think that "the wolf, it should be allowed to live"... Yes, we agree, but not in our area! [...] everything is on government and parliament level, that's where decisions are made, it's there where they say compensation levels should be on this level, the carnivore census should be (like this) [...] It is terribly hard for us to reach up there because we don't have these large lobby organizations that really can carry out lobbying towards the parliament and the government. [...] There are strong lobbyist forces, but we don't have that kind of knowledge and experience [...] ...we don't have the financial resources, either. [...] And the Sami Parliament, they don't have enough resources, either...

Joel: In the first step the challenge (of reindeer husbandry) is of course to deal with all the vagaries of nature [...]. But then it is a challenge to try and get acceptance for reindeer husbandry and the needs of the reindeer in society. To secure the pastures of the reindeer, etc, that's a major challenge. That is, to say, win acceptance for these Sami rights. [...] We want more influence in land and water management. Without asking for our own state, but... we want greater respect for our rights.

Lisa: There are many challenges, but the biggest one right now is the carnivores, and it is not the carnivores themselves but to manage the fact that we don't have a right... first, we are not believed, second, we don't have a right to protect ourselves, in any way. And if we would do it and use the little legal room we have, we are questioned. [...] It is paragraph 28. With that package comes an investigation regarding whether you have made the right decision. So there is no... I think it's that you don't have any power over your own situation, that you can't affect it, I think that's it. [...] We slaughtered 93 reindeer, but we used to slaughter 2000 a year. So we developed something called the Jinjevaerie report. We went to the County Administrative Board and said we are going under. Then they told us that in that case you have to present it in numbers, and we worked for three months intensively and presented a 30, 40 pages long report. [...] 
Nothing happened, we didn't even get permissions for hunting of problem carnivores. So the only thing proved for us is that we don't get any help whatsoever, it's better to just be quiet and deal with it alone. [...] They [the authorities] assume that we only want to get rid of them [the carnivores], that, if we would be let loose we would be like some wild cowboys... round the forest and shoot everywhere, and then they're all dead, something like that. It feels like there is such an attitude, and therefore the question never comes, "how would you like things to be?" [...] Many times I have thought that it would be so easy if I didn't have such a deep relationship (to the reindeer), because then one would have read the balance and concluded that this does not worked, and changed occupations. [...] you think, yes... No, now I've had enough, if I sell I will have this and that much money and can pay off the loans, etc. [But] it's always the same thing, you have sort of a religious experience in spring, and you think, "sure enough I'll fight for this, because if you give up, then the other side has won. Yes, majority Sweden.

Another recurring topic was that of intrusions into the pastures by resource extraction and other kind of economic interests. This was identified as a main reason as to why reindeer husbandry has had to change:

Ingrid: Forestry has made it impossible to conduct reindeer husbandry in the way my father did, when he was out skiing... In those days you could stay in an area and be there... Now those areas don't exist.

Hans: They have been logging terribly, so there's no resemblance...

Ingrid: ...wind power, hydro power...

Joel: The Swedish fell landscape looks as it does today due to reindeer husbandry. I'm not sure it would have looked like this if we had been absent. [...] We are the only kind of workers that see the total chain of events in the landscape. As I said, we wander from coast to coast, we meet all the people. We see when there is a new clear felling for example, we see when there are new roads, we see when there is wind power, hydro power, we see the mine, we see the outdoor recreation, the demands of the hunters... We see all of that, the total land usage.

For Lisa, land development in reindeer colonialist implications:

There is a massive pressure from the entire Western world right now to use these lands. And I think it's terrible. During hundreds of years, at least for 200 years the Western world has built its riches on the land of indigenous peoples, across the planet. And now the West intends to become environmentally friendly, and it it's supposed to take place on the lands of indigenous people, on their expense, again, I think it is horrible. [...] The environment is supposed to be in a certain way, there are sustainability strategies, it's supposed to be green... This green electricity requires vast amounts of land. [...] And then we are supposed to move over a little, and the companies say, it is such a small part of your lands, you can go a bit in that direction... [...] Where can we go? There is not land for everyone if... we have to move for everyone else. [...] I think there is an agenda for reindeer husbandry in Sweden, I am convinced. [...] That it's not necessary to have that many Sami villages. It might be enough with Norrbotten (the northernmost part of Sweden). [...] Yes, to open up areas for other things. Yes, tourism, immigration as well. The counties have an outspoken strategy of having a lot more people, and it requires land, it brings disruption.

\subsubsection{Relationship to majority Sweden - belinging to a minority}

When asked about what it means to be Sami in Sweden today the informants started discussing their relationship with the general public. The main theme of this topic was the latter's lack of knowledge about Sami culture and reindeer husbandry, and subsequent lack of understanding and sympathy of the carnivore situation for reindeer herders. Sven identified a reason for this in the fact that the majority of Swedish people today don't live close to nature:

Sven: [...] But in those days more people lived of what the forest had to offer. [...] Then they don't tolerate competition with the carnivores, they don't tolerate competition with the wolf. But that's a part of Swedish history which is forgotten today. As I see it, now... we live approximately in the same way (as then), and probably a little sheep farmer somewhere is trying as well.

Ingrid: ...the knowledge among people today has diminished completely because of it (lack of contact with nature)... ...more vegetarians, more animal rights activists, and so on. They protect something they don't really know of.

Sven: ...if they had known how... what the reality is like, it would have been different. They would have been kinder so to speak. There was one time when we shot three bears here, and all hell broke loose, they called us like crazy and especially one, one woman. But I explained what things were really like, and then they became friendly, "oh that's akward, we thought you were some kind of savages up there who killed off everything", and we became real friends. [...] Had they known (nowadays) what reality is like (for us), there would be less (complaints).

Joel: Of course it affects us. [...] All these comments where people can write and spew out virtually anything about reindeer husbandry and the Sami. [...] I question the usefulness of such forums. [...] One concludes that the average Swede has very little knowledge about Sami. Sami and reindeer husbandry. [...] There is very little education in school. [...] Many know more about other indigenous peoples, for example Native Americans in the US and Canada, than what they know about their own indigenous people. [...] So, there's a lot to do about information, a lot of prejudice exists 
Lisa: It is really tough. It has always been tough. There was a period recently when it was a bit trendy with indigenous culture, and we could ride along. But now the winds are starting to blow coldly again. It always happens... It is probably this national minority law that has done it with the road signs and so forth...You know, the arena has a certain size and now it is supposed to be shared with someone else, then someone has to shrink theirs. [...] Sweden and Norway are stupid, we have the only migrating reindeer husbandry on Earth, but it is not utilized at all. They fight with carnivore politics, but take a look at the global perspective, how unique is the wolf? [...] The unique thing about the Scandinavian Peninsula is reindeer husbandry, and it is not made use of at all. It is very surprising.

A recurring topic was frustrations with expectations on how Sami should live 'authentically':

Hans: But you see, it's like this, reindeer husbandry evolves as well, he does not stand still. It's like all other development in society, there are no lumberjacks in the forests with chainsaws, now machines take care of that as well. So every time when you end up in a discussion it is "why don't you use skis, why don't you do this or that?". Well, we shouldn't we be allowed to develop? We're supposed to live in some kind of medieval age from way before...

Joel: One thing that really ticks me off is this (people say) that if the Sami reclaimed their traditional knowledge, they would be able to live in harmony with both wolf, bear, wolverine and all of that, but that's... totally wrong. [...] For example, in the past you had to guard against the wolf, and it is the animal that causes most trouble. But you would still come out on the losing end, many Sami families became reindeer-less even if they stood by their herd and guarded, [...] of course technology facilitates tremendously. And reindeer husbandry is... If I put it this way, all these infringements, all these cumulative effects from all the intrusions, both from forestry, infrastructure, hydro power, mines, you have wind power, outdoor recreation activities... We unfortunately have to try to adjust to everything this has brought, and then technology is a way for us to deal with it. [...] But of course there is also the fact that we are modern people and want to have a good life and family life. Technology makes it possible that even if you work far from your family you can return home quite quickly and participate in family life, and also, in today's society it is not possible to run around in the fells for months, out of touch with civilization, it doesn't work.

\subsection{Matching of interview data against nature and wildlife concepts}

Concept 1: Man's place in nature (Subjugation/Domination)

Joel describes that a reindeer herder must "yield to the vagaries of the weather and the needs of the reindeer", further, "it all depends on the behaviour of the reindeer, what season and weather it is, what the conditions of the pastures are, and so forth". Lisa, in her story about reindeer that won't do as she want, describe the solution not as forcing the reindeer, but rather understand the reason for the behaviour and act accordingly. In both cases we find an example of subjugation, to the forces of nature, and the will of the reindeer, respectively. Instead of reshaping their world according to the Western paradigm, the reindeer herders accept that they have to adjust to natural conditions in their daily life. Further, Lisa's account of performing rituals after having killed a bear in order to appease its spirit connects to this concept as well. This demonstrates that the ancient rituals around bears that Joel talks of are still around in some form. In performing the ritual Lisa acknowledges that there are forces that can't be controlled, but might be persuaded to treat you favourably, if given the proper respect. While the informants in the group interview do not display expression of typical subjugation values, they do not express domination values, either. Overall, subjugation values dominate in this category.

Concept 2: Perception of nature's value
(Intrinsic/Instrumental)

The informants consistently oppose resource extraction and land development within the reindeer herding area. This is understandable from a purely practical standpoint since reindeer husbandry by its very nature requires vast expanses of continuous land without major disturbances. However, it is also evident that they don't only value the landscape as the source of their livelihood. When asked about the role of reindeer husbandry in Swedish society, Joel brings up the aspect of reindeer herders being vigilant when it comes to land development and points out that they have a broad view of what happens in nature that others might miss, implying that awareness of the degradation of the natural environment is of common interest to both Sami and majority Swedes. Both Joel and Lisa also emphasize that Sami culture never resulted in "concrete monuments", cities, etc. Lisa generally laments the exploration that has taken place in the Swedish north during the last 100 years. Overall, these are more protectionist values than traditionalist, clearly displaying an acknowledgement of and appreciation for nature's intrinsic value.

Concept 3: Wildlife Value Orientations
(Mutualistic/Utilitarian)

Animal husbandry is something of a symbol for the traditionalist way of life where nature should be tamed and utilized for man's benefit, i.e. utilitarian values should be predominant. Upon inspecting the Sami's relationship with their reindeer, however, a different picture emerges. In general, the informants in the group interview are not very emotional in their descriptions about the reindeer, but Sven at one moment mentions "the feeling for the reindeer" as a constant part of reindeer husbandry, living on despite modernization. Further, he at one point shares his view that it is indeed the reindeer and not its herder that possesses the right to live off the land. Joel is clear about having "great respect" for the reindeer, and his desire to treat it with "reverence and respect". Even when inevitably having to 
slaughter reindeer, respect is an important element, even for the remains of the slaughtered animal. Lisa speaks of "bottomless love" towards her reindeer, and a strong desire to protect them from harm. She further describes seeing reindeer calves being born in spring as a "religious experience" and the prime motivation to carry on with reindeer husbandry despite economically unfavourable conditions. She describes slaughtering reindeer as very hard, that she has to repress her feelings for the animal to some degree to be able to carry it out, telling herself it is for the good of the whole reindeer herd. Overall, this degree of caring for ones animals, feeling an emotional bond towards them, and even ascribing them rights are typical expressions of a mutualistic value orientation towards animals.

Further, these positive emotions were not limited to reindeer, but were also expressed when predators were discussed. Lisa expresses carnivores as "impressive" and that she feels "delight mingled with terror" when observing them. Especially the bear is described as an impressive animal, and Lisa draws parallels between her own motherhood and that of bear mothers, even recognizing common techniques for child rearing. Joel, in turn describes the bear as intelligent and that it can display fascinating behaviours that makes him wonder about exactly how intelligent it is. Sven in turn describes how his parents had a bear as a "friend". Overall, when talking about carnivores as a collective and about the bear in particular, there clearly are positive dimensions to their existence, and consistent with a mutualistic value orientation.

The wolf however seems excluded from positive descriptions. While both Joel and Lisa both acknowledges it as "powerful", it is to describe the severity of its destructive aspects. The informants' relationship with the wolf will be discussed more thoroughly in the next chapter.

\section{Concept 4: Need structure (Post-materialist/materialist)}

Animal husbandry as a lifestyle is commonly associated with materialist values. All informants however claim that money is not their primary reason for being reindeer herders. Ingrid says "this is not just a job, it is a way of life". She also elaborates on the many ways in which the reindeer is the pillar of the whole Sami culture, their prime source of identity. Joel says money is "not the goal", but instead refers to pride, being out in nature, and the connection with the animals as the prime sources of satisfaction. Further, Joel too describes how reindeer husbandry constitutes a "strong culture, a strong identity", for himself, as well as for his children, a source of security. Again, Lisa described her satisfying relationship with the reindeer as the primary joy of her occupation, even concluding that "if it wasn't so deep, I would have checked the balance and changed jobs". This overall focus among the informants on non-material values such as self-expression and quality of life indicates a post-materialist need structure, in turn being connected to protectionist views.

\section{Concept 5: Access to social power (High/low)}

An overall theme among the informants is dissatisfaction with the current carnivore policy and frustration over not being able to either change it or respond to it the way they would need to. Ingrid talks about lack of resources for effectively carrying out lobbying, and Lisa complains that her efforts to seek help has been ignored, she even thinks that Sami interests are being actively worked against by the authorities. Beside their relationship to the government, the informants also feel exposed to prejudice and lack of understanding by the majority society. Ingrid and Lisa both claim that if they were to utilize the self-defense paragraph 28 and shoot an attacking predator, there will be public repercussion, discouraging them from exerting the little possibility they have to control their situation visa vi the carnivores. Overall, informants generally perceived their access to social power as low.

\subsection{Summary of data-concept matching}

Of all themes explored, only "access to social power" was consistent with the theoretical prediction for livestock owners. Overall, the informants displayed mutualistic value orientations towards animals, acknowledged intrinsic values of nature, emphasized non-material values and displayed protectionism.

\section{Discussion}

\subsection{Nature and wildlife values of the Sami}

The informants consistently expressed values about nature and wildlife that is more commonly associated with highly educated, high-income urbanites than with rural pastoralists. It is clear that the Sami does not readily fit into this dichotomy, as they seem to have more in common with the urbanites, value-wise, than other rural people. Nevertheless, the Sami are in opposition of the current carnivore management in Sweden, and express high mistrust towards the government. While it is clear that differences in fundamental beliefs of the value of nature are not the issue here, we must look for a different explanation, which might be found in the specifics of the environmental beliefs of the Sami.

While having adopted protectionist values towards nature, as well as a mutualistic way of relating to animals, modern world urbanites ultimately live their lives separated from nature, which might affect their perception of their own place in it. Like Joel points out when discussing the exclusion of people from natural reserves, it is as if man does not belong in nature. By excluding man from nature, we protect it, leave it to its own devices and enjoy it from a distance. Indigenous peoples, however, fundamentally thinks that man belongs in nature, as a natural part of it with all other species. As made evident by Joel's comment about a landscape without humans is strange, this view exists among the Sami as well. In the indigenous mind-set, 
man does not threaten nature, rather, nature can threaten man if we don't treat it respectfully. This is the case with the Native American Ojibe tribe and their "keepers of the game" concept, as well with modern Sami still performing rituals when having killed a bear to pay respect to its spirit. Thus, both the Sami and Swedish urbanites have mutualistic values towards nature, but their very definition of nature is different; this has implications for the conflict about the wolf and carnivore policy in general (see below).

\subsection{Need structures - materialism vs post- materialism}

The informants expressed values more consistent with a post-materialism worldview than a materialist one. It is however unlikely that these values are a result of exceptional material affluence, given the economic hardships the informants were facing in their daily lives. Rather, it could be argued that the informants' focus on non-material values express a form of "pre-materialism" which has survived despite modernization of reindeer husbandry and demands for profitability from the rest of society. Lisa's comment about living in a "market-based world" contrasting it with living in a "biological world" illustrates this, as well as the fact that the demands of the "market-based world" make it harder for the Sami to coexist with the carnivores. In sum, one can argue that despite increasing pressure of majority society, the core of Sami reindeer herders' priorities in terms of need structures remains intact.

\subsection{The Sami and the wolf - an issue of social power}

The Sami experience significant public backlash through rejecting the presence of wolves in the reindeer husbandry area. On a first glance, their stance might seem unforgiving and standing in contrast to their self-purported holistic view of the natural environment. It is however important to understand, that while reindeer herders might be rejecting the wolf wholesale, this is done in a context where defending against it have severe legal as well as social implications. While the wolf has always been a competitor for their livestock, the wolf has now taken on additional negative connotations through its high level of protection and public support, which contrasts with the Sami's relative lack of social power and sympathy among the general public. While the wolf might always have been a troublesome animal for reindeer husbandry, possibly also more so than the other large carnivores, to the Sami it has now also become a powerful symbol of the Sweden majority society's disregard of, and even opposition to, Sami interests. To majority Sweden, however, the wolf is a symbol of environmental comeback and natural integrity, and the Sami point of view is interpreted as backwards and environmentally unsound. Thus, the wolf, as a projection surface for conflicting perspectives, but in this case, not necessarily conflicting basic environmental values, becomes a source of polarization between the Sami and pro-wolf stakeholders. At such, it also becomes the focal point for the clash between conflicting views of how what is a healthy environment, and what sort of management is appropriate for achieving it.

\subsection{Conflicting views of "nature"}

As protection values become increasingly prominent in the majority society, they are being superimposed on the reindeer husbandry culture as well, with significant social friction being the result. However, it is not lack of concern of environmental issues on the part of the Sami that causes friction with majority Sweden. Rather, it is the failure of majority Sweden to understand and acknowledge that protection values are very much present in Sami culture as well, however in a form relevant to the conditions of their specific situation, which causes the friction. All informants expressed frustration with this, the fact that their understanding of balance in nature, a balance where man has a place, is not recognized, and they are not entrusted with maintaining this balance, despite hundreds of years of experience of doing so. To add insult to injury, majority Sweden add another kind of pressure in the form continuous exploitation of traditional Sami land, extractive activities that very much are a manifestation of materialist, utilitarian values. Even when such land development has politically "green" purposes, such as production of renewable energy, the effects on the landscape is one of environmental degradation, which is mostly felt by the reindeer herders living there. Lisa even refers to this as a new wave of colonialism, where "clean energy" is produced by, and mostly for, majority Sweden at the cost of the Sami. The result is a resounding "do as we say, not as we do" from majority Sweden, as the same outside force that demands "eco-friendliness" from the Sami and scolds them for not measuring up to the standards of their definition of it, itself perform actions that are very much the opposite.

Seemingly, we have two different views of "environmentally friendly", a Swedish one and a Sami one, each with different priorities. While the Swedish agenda focuses on clean energy production and conservation goals for individual animal species, such as the wolf, the Sami are more concerned about the overall integrity of the natural landscape they operate in. It can be discussed which one of these views is more correct. As for land development for renewable energy, the negative environmental effects on a local/regional level are very real in terms of disrupted connectivity affecting the migration of reindeer, and subsequently, the practices of reindeer husbandry. The reindeer are dependent on a high degree of connectivity in the landscape in order to successfully carry out their migration, and consequently, to provide their ecosystem service in the form of vegetation maintenance by grazing. Large portions of the biodiversity in subarctic Sweden are dependent on the reindeers' continued success at doing so. Large carnivores, however, are not among those species. It 
has been argued that if left alone by humans, large carnivores are capable of surviving or even thriving in comparatively degraded landscapes with low levels of biodiversity, much like the moose is capable of thriving in industrial forest. To environmentalists, the wolf is typically a symbol of ecological reconciliation and environmental integrity, given its important regulatory ecological function as demonstrated in Yellowstone National Park. In the context of Northern Sweden however, a healthy population of the wolf might not be a good indicator of an overall healthy environment, given its high tolerance for environmental degradation. Rather, continued annual migrations of the reindeer and enough green infrastructures to support might be the reliable indicator. In order to control reindeer population size in Sweden the wolf is not necessary since another apex predator, man, in the form of reindeer herders, is already doing that. Further, the wolf won't oppose further land development to protect the rights of the reindeer, but the reindeer herders very much do. While the wolf undoubtedly exerts a huge environmental influence on ecosystems where man is not present, such as Yellowstone National Park, it is rightfully deserving of its status as an environmental icon. However, this iconic status might not make the wolf ecologically relevant for natural systems where man is the primary influence. For such contexts, such as the reindeer husbandry area, it is important to look beyond the political and symbolic status of the wolf in order to make a sound assessment of its true ecological value.

\section{Conclusion and recommendations}

At first glance, reindeer herding Sami might seem like the classic rural pastoralists protecting their economic interests, and as such being opposed to environmental policy. Further investigation however reveals that this is not the case. Despite having undergone significant technological development and being organized in profit-driven companies their original mutualistic, protectionist view of nature and wildlife, characteristic for indigenous peoples, is very much alive. Thus, the conflict around the wolf in Sweden is not foremost a conflict of clashing environmental values along the utilitarian-mutualistic value orientation scale, such as the case with the Greater Yellowstone area. Rather, it is a conflict between two different mutualistic value systems, each with their own definitions of a healthy environment and different priorities for achieving it. While the environmental agenda of majority Sweden prioritizes charismatic animal species like the wolf, the Sami prioritizes the integrity of the natural landscape. Thus, the dichotomy of utilitarian/traditionalist-mutualist/protectionist values associated with the rural-urban boundary, as described in previous literature, is not really applicable here. Clearly, when studying the human dimensions of human-wildlife conflicts where one of the stakeholders is an indigenous people, it is important to not assess the situation only through a Western understanding of nature and environment, since the true position of the indigenous then might get misinterpreted. Conflicts involving indigenous peoples, who are typically underprivileged, must also be understood from a perspective of social power. The Sami, already pressured by various infrastructural, legal and moral infringements of their way of life rejects the wolf, maybe not foremost as an animal species, but as a symbol of governmental oppression. Fundamentally, it is a story of miscommunication and mutual distrust between the Sami and majority society, involving a great lack of understanding and sympathy for the Sami position. It is clear that the Sami are not foremost opposing carnivores themselves, but the management of these, and the fact that they have little to no saying in this issue, although they are among those feeling its effects most acutely. If the Sami are given a higher degree of participation in planning, decisionmaking and management of carnivores, as well as in other issues affecting them, the social tension between them and the government is likely to relax. The Sami have hundreds of years of experience of managing the natural environment in which they have operated, manifested in a wealth of traditional knowledge. For this, they at least deserve recognition and respect. Further, if we are prepared to let go of some of our prestige, they surely have things to teach us that are relevant to contemporary environmental management as well. That is, if we are willing to listen to their story.

\section{Acknowledgements}

Thank you Professor Makoto Yokohari for conceptual guidance and support and thank you Dr Tanaka Toshinori for hands-on advice for data analysis.Thank you Professor Hirotaka Matsuda for feedback and comments on the draft for this paper.Thank you Professor BirgittaÅhman and Dr Anna Skarin for valuable insights on the conditions of reindeer husbandry and thank you DrHåkan Sand and Camilla Wikenros for insights regarding the ecological and genetical status of wolves in Sweden.Thank you HåkanTunon for providing valuable literature on the ecological function of reindeer husbandry in Sweden.Thank you Ann Dalerus for providing a "third party" environmentalist perspective.Thank you BjörnJonsson, Helena Eriksson and Magnus Bergström for insights on Swedish carnivore policy and government-Sami relationships on regional and national levels, respectively. A special big thanks to RuonaBurman for further insights on Swedish carnivore policy, for introducing me to reindeer herders and for logistics during my field work. Last but foremost, a big thanks to all the participants in my interview service for providing your time and insights, without you this study would not have been possible at all. 


\section{References}

[1] Woodroffe, R., Thirgood, S., \& Rabinowitz, A. (2005). People and Wildlife - Conflict or Coexistence? New York: Cambridge University Press.

[2] Choudhury, A. (2010). Human-Elephant conflicts in Northeast India. Human Dimensions of Wildlife: An international Journal, 9:4 261-27o.

[3] Granados, A., \&Weladji, R. B. (2012). Human-Elephant Conflict AroundBénoué National Park, Cameroon: Influence on Local Attitudes and Implications for Conservation. Human Dimensions of Wildlife: An International Journal, 17:2, 77-9o.

[4] Woodroffe, R., Lindsey, P., Romanach, S., Stein, A., \&Ranah, S. M. (2005). Livestock predation by endangered African wild dogs (Lycaonpictus) in northern Kenya. Biological Conservation , 225-234.

[5] Breitenmoser, U. (1998). Large predators in the alps: The fall and rise of man's competitors. Biological Conservation, 83:03 279-289.

[6] Conover, M. R., \& Decker, D. J. (1991). Wildlife Damage to Crops: Perceptions of Agricultural and Wildlife Professionals in 1957 and 1987. Wildlife Society Bulletin, 19:1 46-52.

[7] Patterson, M. E., Montag, J. M., \& Williams, D. R. (2003). The urbanization of wildlife management: Social science, conflict and decision making. Urban Forestry \& Urban Greening , 1, 171-183.

[8] Wilson, M. A. (1997). The Wolf in Yellowstone: Science, Symbol or Politics? Deconstructing the Conflict Between Environmentalism and Wise Use. Society and Natural Resources, 10, 453-468.

[9] Scarce, R. (1998). What do wolves mean? Conflicting social constructions of Canis lupus in "bordertown". Human dimensions of Wildlife: An international Journal, 3:3 26-45.

[10] Nie, M. A. (2001). The Sociopolitical Dimensions of Wolf Management and Restoration in the United States. Human Ecology Review, 8:1, 1-12.

[11] Goldman, M. J., De Pinho, R. J., \& Perry, J. (2010). Maintaining Complex Relations with Large Cats: Maasai and Lions in Kenya and Tanzania. Human Dimensions of Wildlife , 332-346.

[12] Pierotti, R. (2010). Sustainability of Natural Populations: Lessons from Indigenous Knowledge. Human Dimensions of Wildlife: An international Journal, 15:4, 274-287.

[13] Sapmi. (n.d.). Accessed 23 July 2014, from www.samer.se

[14] Sametinget. (n.d.). Accessed 23 July 2014, from http://sametinget.se/66807

[15] Lagen.nu. (n.d.). Accessed 23 July 2014, from https://lagen.nu/1971:437

[16]Tunon, H., \&Sjaggo, B. (2012). Ajddo reflektionerkringbiologiskmångfald i renarnasspår ("Ajddo - thoughts on biodiversity in the tracks of the reindeer"). Uppsala and Kiruna: Naptek, Centrum för biologisk mångfald och Sametinget.

[17] Government of Sweden. (2012). Government Bill 2012/13:191 "En hållbarrovjudrspolitik" ("A sustainable carnivore policy"). Stockholm: The Government of Sweden.

[18] Sikku, O. J., \& Torp, E. (2004). Vargenärvärst ("The wolf is worst"). Uddevalla: JamtliFörlag.
[19]Ericsson, G., \&Heberlein, T. A. (2003). Attitudes of hunters, locals and the general public in Sweden now that the wolves are back. Biological Conservation, 111, 149-159.

[20] Ryd, Y. (2007). Ren och Varg - Samer berättar ("Reindeer and Wolf - Sami tell"). Stockholm: Bokförlaget Natur och Kultur.

[21] Uddenberg, N. (200o). Renarna, markerna och människorna ("The reindeer, the land, the people"). Nora: Bokförlaget Nya Doxa.

[22] Manfredo, M. J., \&Dayer, A. A. (2004). Concepts for Exploring the Social Aspects of Human-Wildlife Conflict in a Global Context. Human Dimensions of Wildlife: An international Journal, 9:4 1-20.

[23] Fulton, D. C., Manfredo, M. J., Lipscomb, J. (1996). Wildlife value orientations: A conceptual and measurement approach. Human Dimensions of Wildlife $1: 2$ 